\title{
The Interpretation of Chinese Traditional Culture by Lin Dan badminton Aesthetics
}

\author{
Yang $L u^{1, a}$ \\ ${ }^{1}$ Department of Physical Education, Wuhan Polytechnic, Wuhan, China \\ a120804148@qq.com
}

Keywords: Lin Dan; badminton; aesthetics; Chinese traditional culture; style.

\begin{abstract}
Lin Dan's badminton is full of art, he will be turned into a more in line with the badminton movement Chinese understanding. Through literature, the Internet in the analysis of Lin Dan's reports and case found that Lin Dan's style of traditional culture Chinese badminton permeated with the shadow, the transmission of traditional culture China flash point: in the western financial learn widely from others'strong points, Lin Dan speed assault another revolution to promote play badminton; the sun Tzu Chi and the badminton, to learn to play with my mind, to change the status quo; a statue of Shang Tianren Ren Chong, advocating noble character and great boldness; unremitting self-improvement social commitment decided the outcome of the game, the key is the inner sword of Mo Liying; male hardships experienced failures and frustrations withstood pressure from all sides to make a difference. Why is this China audience obsessed with Lin Dan.
\end{abstract}

\section{Introduction}

Lindan in Olympic Games, world championships, world cup, the Thomas Cup, Sudirman Cup, Britain race, FIBA Asia Championships, Asian Games champion in the "super grand slam", he created a belongs to own time, created the badminton a may never copied myth. At present, a total of 19 world champions, into the history of the first person. Lin Dan led the assault speed play badminton technology revolution, his diving save ornamental wonders, his ability to control has been perfected. In addition, Lin Dan occupation career international tournament 57 gold medal history first.

Chinese mainly includes the traditional culture of Confucianism and Taoism, Buddhist culture, after a long time development and precipitation in the process of the development of the Chinese nation has always played a role, and the main culture and the formation of a Chinese characteristic way of thinking and life style. The style is not the soul of badminton. Badminton style refers to reflect the characteristics of athletes in badminton team and the tactical characteristics of one of the national spirit and national cultural characteristics summary. The badminton style is created by traditional culture, national characteristics, regional characteristics and other complex factors, play badminton as the soul is better or worse without the points, but the unique style as long as up to a certain level will reveal its unique artistic charm and competitiveness. Lin Dan badminton style permeated with the shadow of the Chinese traditional culture, the transmission of the flash point of the Chinese traditional culture, the growth process for many Chinese athletes, especially Chinese sports stars is a very good example. Because to maximize their value, is an athlete on their own, to engage in their own sports, as well as the whole of society, one of the best contribution.

\section{A Chinese traditional culture characteristics in western finance learn widely from others'strong points}

Olympic culture is a kind of strong culture, its original cultural characteristics initially almost solely in europe. Badminton is the most direct predecessor is India Pune "'." Similar "Pune" activities as early as the world is widespread, Japan's cherry badminton, Russia's "Fu Lang", the British "shuttlecock Cricket", "China's play chicken feather ball" are very similar. "Human nature and animal feathers, wind, temperature, humidity, light and other natural products for the fight between the opponent." Badminton is a "green" sport, with the "harmony between man and nature" of the oriental 
culture retained. There are great differences between eastern culture and Western culture, to Chinese and India with the table of Oriental culture is based on Confucianism "and" Buddha "as its core, is the" Rites "culture, can not find a" dispute "in eastern culture vocabulary. While relying on the western industrial civilization advocated "competition", worship of power, is a kind of "Chang Yin" hero worship culture. "Pune" into England, competitive factors are amplified to become modern sports.[1]

China first badminton is absorbed by the technical wisdom of overseas Chinese, then learn the Chinese table tennis team and Japanese volleyball team experience, from Marx, Mao Zedong got the hands of sages "Dialectics" the Pearl of wisdom. Create a "fast and hard, accurate and flexible" China style and "me first, mainly to the fast, to attack the main" guiding ideology, the Chinese athletes in badminton technology towards fast, flexible, attack direction.

Five thousand years of Chinese civilization splendid history, showing the history of genetic inheritance and the overall good, excellent badminton sports history in the generations of people who care and management of badminton, and made brilliant achievements today. Such as Hou Jiachang, Tang Xianhu, Yang Yang, Zhao Jianhua, Han Aiping, Li Lingyu, Li Yongbo, Tian Bingyi, Sun Jun, Ge Fei, Gu Jun, Zhang Jun, Gao Ling and so on. These players formed a uniform and with the overall China Badminton style and mode of development, by Chinese traditional culture and the spirit of the internal formed a unique fixed forms of cultural expression and reflect injection promote the behavior pattern of the development of the Chinese badminton, thinking orientation and value orientation. Hou Jiachang and Tang Xianhu create the so-called "Wumianzhiwang" Chinese badminton "Tang Hou era". In the international arena, Tang Xianhu was created in 1963 to 1975 of 12 years has not lost a unbeaten record.

Chinese badminton technology style, both lasting tactics both physical consumption, while also playing the onslaught of quick attack characteristics. It requires athletes ingenuity, durability, accuracy, emotional stability, fight each other's weaknesses. Theoretically, this play is the best, but to do is not easy, at least to have a certain talent and skill. Chinese coaches for athletes to develop this tactic, at present only a few outstanding athletes can meet the requirements, once the requirements, in the scientific training and guidance has made remarkable achievements. Representative figures of lindane, his left hand grip and technical characteristics is pull hanging surprise play mainly, start fast, good placement attack, attack sharp, explosive force is very strong. The main expertise lies in the backcourt assault fierce, offensive ability, flexible pace, smash very threatening. Its originality, the change in pitch angle to smash, large split hanging is the biggest killer, transmission assault is to promote the play of Lin Dan and a technical revolution of badminton.

\section{Chinese traditional cultural characteristics of Jiu Sunzi's art of war and rule badminton}

The art of war and even China traditional culture is not only to bring the strategy of badminton players is a tactical guidance. Wits is the charm of badminton athletes, in addition to high in technology and endurance requirements is more important to learn to play with my mind, maintaining the status quo.

The badminton court and the battlefield almost, sports arena is "abnormal" battlefield, "wind, forest, fire, mountain" from the "art of war" - armed struggle "in the" military action ", in the military status, influence and War produced, are absolutely vital," means to achieve the wind, forest, fire, mountain "is the grandson of strategy. And as a tactical classic "grandchildren strategics", not only can bring strategic guidance to the badminton players, can bring to Tactical Guidance "the swift as the wind, the $\mathrm{Xu}$ Rulin, aggressive as fire, do not move a mountain", is the representative of the badminton movement speed, versatile, powerful, defensive. [2]

Due to significant changes in the 21 points system to bring the badminton competition, the tactics of world badminton movement towards a more rapid, comprehensive, offensive, changeable, long prominent "the direction of development. To a more rapid development of badminton technique and tactics direction is still an important aspect of the general trend of. The basic conditions of the top athletes of the world possess is the ability of fully mastering and using the basic technology in rapid motion; reflect the rapid ability to focus more on the speed of attack, attack technology is more 
focused on fast and fierce development of personal characteristics on transmission technology of assault. European players use the advantage of the body tall and powerful, has been from the emphasis on control line play to emphasize and highlight the offensive attack after service, following pressure control is the main direction of the development of the net game. Asian players are more focused on the use of its own mobile flexible features, highlighting the development of transmission technique based on a comprehensive assault, mainly to pull with variable assault style. Although the players in the tactical organization on its different characteristics, but in a prominent fast attack, stressed that the two aspects of the threat and attack efficiency is improved in common. At the same time, to fight for the net is getting more and more intense. In addition to grab high hit the ball outside, the changes of net technology and high quality control net ball, has become the main means of the opportunity to attack and score high level athletes to gain. The new rules make the game change quickly, with a lot of chance and unexpected. The athletes should not only have excellent and comprehensive technical and tactical ability, and have ability to deal with all kinds of complicated situation. This ability is composed of consciousness and technical and tactical ability of the combination of technology, tactics, physical quality, intelligence, psychology and will complete competition strategy.

Athletes of different styles, is essentially attributed to the different systems, different technology systems inevitably show different styles of technology, but technology system itself and the formation of national culture and the environment there is an important relationship between the technical style in the process of formation is often affected by the important influence of national culture. Influence of environment and culture of style is imperceptibly, is subtle, which belongs to the implicit cognitive function of human being. The implicit cognition of a regional or national culture by the people with a robust way for athletes, the specific performance of these cultural or environmental knowledge is athletes with different carriers (such as social communication, culture learning) athletes heart and down quietly into the depths of the soul in the accumulation of technical training, performance for athletes, so as to promote the technical style of the formation and maintain the stability of the style. Of course, the whole process is unconscious, is not for the athletes perceived. The national culture and environmental knowledge, which is not aware of the athletes, have been involved in the social cognitive process, including the formation of technological style, which is a kind of subtle transfer effect ".[3]

Chinese athletes are not physically high, power is not, but flexible. Based on the badminton technology characteristics of Chinese athletes in the shot, smash, the lob, net ball (rubbing, push, hook, flapping) etc. the comprehensive development and utilization. Tactics have also been more comprehensive development, from the past to play ball tactics to pull hanging around the assault, keep in a series of offensive play. The representative Lin Dan ball like a clever, he is not a particularly good game player, but his balls have a ready pen is very impressive, pay attention to the feel of the ultra high requirements, since his 2005 World Championships after the defeat he will gradually opened the change for assault defense after the assault began play from the active position to active assault each other apart the other anti assault in the multi shot in each position and his sudden opening of this play requires patience also need more placement support, the 2006 Asian Games men's singles final defeat in fact clearly shows his improper placement and the control of the rhythm of Toufik's net position of defense is not clear on 2007 is his placement change at the beginning of the pursuit of abnormal strength to support his accurate placement and speed to a new height in the 2008 Olympic Games began to see more of Lin Danyong The finger in the control and placement of the ball Lin Dan more accurate ball more subtle in such a good physical talent and enough positive brain and famous and some good fortune that he made this achievement, the fruit will be due at the same time, we need to see the results of the analysis of its cause the internal composition may have a better understanding and appreciation of Lin Dan's aesthetics of badminton. 


\section{Chinese traditional culture characteristics is the harmony between man and nature statue benevolence Zonta}

The harmony between man and nature, that is the harmony between man and nature, man and society, and self. China traditional culture requirements $\mathrm{Wu}$ has the noble character and great boldness of vision, modest people do.

In addition to the requirements of the traditional martial arts Chinese attack must comply with the principles of harmony of yin and Yang, move among force and soft, with particular emphasis on the humanity center Takenori, mainly in the martial arts and the unity of self-cultivation, important way and method of martial arts is life moral. At the beginning of martial arts began to learn a few hands, always looking for opportunities to try, if there is no discipline is easy to master with Kung Fu deep, meddlesome, often holding more and more deep, generally not easily with anyone, especially trained to profound teacher, the more practice the more deep inner force, the more deep. This point neijiaquan is more prominent, their goal is not to contest the skill, but the cultivation of their lives. To reach this realm of Wushi, gentle, modest, friendly.

"A lifetime of friends, a lifetime of opponents." This is Lin Dan's description of his opponent. Become rivals, is the fate; defeated his opponent, is the mission; and because there are those Freemasonry, and it is a great duel opponent. Enter the 2013 world badminton men's singles final tiebreaker score into 16-19 Lin Dan lead, Lin Dan a kill forced Li Zongwei to push it, because not a physical, he suddenly appeared leg cramps. After a rest, Li Zongwei return to the stadium, but the re emergence of the phenomenon of leg cramps. Then Lin Dan went to the stadium opposite to comfort Li Zongwei, Li Zongwei announced that after retirement, Lin Dan and others put him on a stretcher. At that moment, two people have apparently not rivals, but friends of mutual respect. Lin Dan and $\mathrm{Li}$ Zongwei are not only the opponent is badminton best friend, from the act, they have gone beyond the competition itself.

\section{Chinese traditional cultural characteristics of unremitting self-improvement social commitment}

A gentleman should be like objects like running off, even if displaced, or if you are a gentleman, refuse to be cowed or submit; make sure to measure the same as the earth, nothing can not bear. Tang Xian tiger 60 years badminton career experience summed up as "soup type badminton training method" to play, only focus on the technical level is not enough, decided an athlete is the intrinsic ability strength limit. "Tactics are the external decisive is the inherent."

Beijing Olympic Games year, Lin Dan as the "South Korea mouth storm" and "Jinjiang incident" and criticism. Lin Dan want to let Tang Xianhu guide their own. In Lin's career had because of experience training to smash racquets was stopped training for 20 days, but in the run-up to the day of the Beijing Olympics, he threw down the racket can be compiled in a row. Lin Dan said: "I also know that this behavior does not fall time, encounter this kind of thing coach usually scold, but the soup guide let you calm down, find out the reason. Because everyone knew is certainly not good mood fell to beat, but why is not good, but very few people to explore. This soup, guide never blame me."

"Stand up, you shout." This is Tang Xianhu and a tolerance for Lin Dan. How to cultivate a world champion? "The most important thing is to see here!" Tang Xianhu pointed to his head. "I often said to Lin Dan, what is the highest realm to fight? Is the mentality! How to solve the difficulties encountered? Positive or negative? It is a way of thinking, this is very important." There is a so-called! Lost to win back. In the Asian Games, Lin Dan won the championship, so excited, why? It is the realization of non win can not believe. With these two points, the rest will come." Tang Xianhu put these two points to the physical quality of the individual before. "Speed, sensitivity, explosive power, strength, energy, endurance, these basic qualities are very important. Pick the seedling on the election of the people, then let them play." The game is also very important. A good state of mind is one of these exercises. "From the first began to adjust their mentality, previously defeated not necessarily 
will win them, every time a different reality, a good attitude is the game win and lose out of adjustment."

"Lin Dan is a personality of athletes. He is definitely not a good student. You want to make him satisfied, you must take to persuade his evidence." For this "evidence", Lin Dan repeatedly TSF error action video, find out the crux of the problem from the "evidence"; in order to overthrow the TSF teaching methods of a few decades ago, summed up the guidance of new ideas. This "state, let Teaching benefits teachers as well as students." Tang Xianhu delight.

Lin Dan on the field of passion, Lin Dan on the training field is hot. Sometimes can not find a better solution, Lin Dan will very irritable, shouted loudly "does not practice", drop the racket, and sped away. Tang Xianhu is neither too fast nor too slow: I will never call him, not to say he is not good training style. I know he is very anxious, he wanted to play, this is his goal. He figured out later, was able to train well." Lin Danfa after the fire, TSF will take the initiative to walk past: "gone? All right, continue to practice." For so many years, Tang Xianhu and Lin Dan never quarrel, this is a miracle in the national team. Sometimes can not help but go away, Tang Xianhu, and Lin Dan thought to practice. [4]

In China such as Lin Dan personality, very difficult to tune the fierce horse has not popular. Through the "fried coach" after the incident, Tang Xianhu was over 60 years, as Lin Dan came back. With Lin Dan through his most impetuous, confused the most competitive low, with their grace and wisdom put him into a mature heart, calm badminton king, thus creating a China behind a series of brilliant achievements in badminton. That year, the Beijing Olympic Games, what is the "let Lin Dan breakthrough, able to perform wonders" skills and mental barriers, then get out of hand to the achievement of "Grand Slam" Albert? Tang Xianhu said: "Lin Dan was the technical level is already very high, for him, the key is to enhance the ability of internal. Usually when training, he looked at me not to talk, a little anxious, ask me, "why don't you speak?" I said, "you have not put in, what I say?"' In the game, as long as Lin Dan turns to see the coach quietly nodded, will be encouraged to understand the ball well.

So, how to enhance the "inner ability"? Tang Xianhu said: "this is the focus of attention, energy issues, have the mentality of the adjustment, self-confidence to enhance, because self-confidence is the 'victory of the lifeline', no confidence in failure. There will be the quality of exercise to enhance, but also to have wisdom, to use their brains to play to play your intelligence. The game hit the most intense time, the fight is actually these."

In the opinion of the soup handsome, this is his most successful promotion of Lin Dan. He said: "by 2008, Lin Dan the people mature." But when it comes to delay Venice Olympic dream Li Zongwei, Tang Xianhu said: "Li Zongwei at that time has a little problem is urgent, hand is not how to listen." [5]

\section{China traditional cultural characteristics of a Polish hero full of sword}

Lin Dan said: "a man may only have experienced failure and frustrations, to become a major event." They come on, you carry it, the whole world belongs to you. If you are defeated, is at the foot of the abyss."

Super Dan is milepost type character and history of the development of badminton, the World Badminton Federation Chairman of South Korea's Jiang Rongzhong praised Lin Dan is "the most outstanding of our era, exactly is beyond the scope of this era, Lin Dan's assault transmission technology to promote the revolution play badminton, he let the badminton game is full of rhythm and aggressive, sometimes good to hear or see, sometimes ups and shock, he is full of unique charm of the badminton ball sports the snapshot! China badminton team coach Li Yongbo once said of Lin Dan: "he is a rare genius."

Genius is hone. In 1995, Lin Dan won the national youth men's singles champion, was immediately picked in the liberation army. That year, Lin 12 years old from juvenile sports school in Fujian team, to later Liberation Army, Lin Dan is always team the best a, all the coaches it like this has a strong force and physical qualities of explosive players. In 2002, Lin Dan in the Thomas Cup and the subsequent few stations open all out in the first round, the nickname "forest round" this called. 
After a rough, Lin Dan finally understand that talent alone is not to win the game. After this, lindane, often in the evening practice, in the subsequent 6 stations open get five championship and a runner up and win their own signs celebrations, salute. In August 22, 2002, Lin Dan won the first in the world for the first time, although only a short week time. 2004 all England Championships, Lin Dan defeated idol Pete Gade win, to further consolidate the world rankings. It is also after the game, Lin Dan was the foreign media called "Super Dan" (super Dan).[6]

\section{Conclusion}

Lu Yunting believes that China disappear is just the samurai warrior warrior, enlightenment, ideal creed and warrior spirit, as a group and the real warrior still exists, they reunite around the highest authority in the country, and to realize their own value. As the modern Knight Arena - athletes, its unique temperament and demeanor are common features of history and culture is the source of modern sports, in constant pursuit of higher, faster and stronger at the same time, the traditional sports culture China's unique value and status will be evident, China traditional culture as an important intermediary, let more athletes to reach an understanding, thinking, and culture will across racial complexion, formed with respect to the excellent traditional culture model, movement in the cultural beauty and noble spirit will spread widely.

\section{References}

[1] Lin Chuanchao. Badminton culture of Fujian [J]. sports science and technology, 2007, (2): 15 - 18

[2] NetEase. Sports sponsorship of Lining China national badminton team [EB/OL]. http://sports.163.com/09/0421/21/57F12C7600053BCU.html. 2009-04-21. series wind racket

[3] Fan Wenjie, Dai Xuemei. The implicit cognition style formed on [J]. Journal of Industrial and Commercial University Of Chongqing (NATURAL SCIENCE EDITION), 2010 (5): 513-515.

[4] I TSF to train a number of "Lin Dan [N]." Yangcheng Evening News, 2011-4-23.

Sina [5] sports. Interview with Tang Xianhu: how can I help Lin Dan pierce the last layer of paper windows? Http://sports.sina.com.cn/o/2015-05-11/22077604531.shtml.2015-5-11. [EB/OL].

[6] Xinhua. Lin Dan: faith and change http://news.xinhuanet.com/sports/2012-07/23/ c_123457156.html.2012-7-23. [EB/OL].

[7] Lu Yunting. Ups and downs in between the city and countryside warrior ghost -- modern sports of China People's interpretation of the spirit of [J]. Sports and science, 2013 (1): 35. 